\title{
CIRCULARLY-POLARIZED, WIDE-RANGE COVERAGE AZIMUTH AND ELEVATION ANGLES MICROSTRIP ANTENNA FOR RF HARVESTING
}

*Hayder Almizan ${ }^{1}$

\author{
Taha A. Elwi ${ }^{2}$
}

Zaid A. Abdul Hassain ${ }^{3}$

1) Department of Electronics and Communications, College of Engineering, University of Kufa, Najaf, Iraq

2) Communication Engineering Department, Al-Ma'moon University College, Baghdad, Iraq

3) Electrical Engineering, College of Engineering, Mustansiriyah University, Baghdad, Iraq

\begin{abstract}
Antenna design considerations of RF harvesting must balance between three conflicted points which are: antenna gain, antenna polarization and antenna coverage angles to reap RF energy. In this paper, a circularlypolarized, wide-range coverage azimuth $\varphi$ and elevation $\theta$ angles rectangular microstrip antenna for RF harvesting is proposed. Circular polarization is achieved by forming 2 diagonal truncated-edges and 4 orthogonal etched-slots in the microstrip patch. A parametric study is conducted to indicate the performance of antenna circular polarization with changing truncations and slots dimensions. A second parametric study of groundsubstrate area effects on the antenna gain shows the ability to control azimuth and elevation angles. This technique is employed to widen the range of coverage antenna angles to the desire specifications. A modelling via curve fitting is made for antenna gain versus groundsubstrate area using polynomial function of second degree. The proposed antenna ground-substrate area is adjusted to reach the maximum coverage anglers within parametric study boundaries. The proposed antenna ground-substrate area is $280 \mathrm{~mm} \times 280 \mathrm{~mm}$ with coverage anglers are ranged $\left(-42^{\circ}\right.$ to $\left.+42^{\circ}\right)$ for azimuth angle $\varphi$ and $\left(-68.5^{\circ}\right.$ to $\left.+68.5^{\circ}\right)$ for elevation angle $\theta$ while antenna gain is almost $1.33 \mathrm{dBi}$. Finally, the proposed antenna is fabricated and tested. The simulated and measured results are matched excellently.
\end{abstract}

Keywords: Circularly-Polarized Antenna, Rectangular Microstrip Antenna, RF Harvesting, Curve fitting.

\section{Introduction}

Fast growing in low-power electronics and communication systems make Radio Frequency (RF) energy harvesting a desirable source of free energy [1]. RF harvesting candidates to be a standard part for a large spectrum of applications including biomedical and military [2].

Design RF harvesting antenna requires to appreciate many points. In this paper, three points of RF harvesting antenna design is considered. The first point is concerned about the received power $\left(P_{r}\right)$ via RF harvesting antenna which is given by [3]:

$$
P_{r}=G_{r} S_{i}\left[\frac{\lambda^{2}}{4 \pi}\right]
$$

where $G_{r}$ is the received antenna gain, $S_{i}$ is the power density of the incident electromagnetic waves in $\left(W / m^{2}\right)$ and $\lambda$ is the incident electromagnetic wavelength in $(m)$. According to (1), $G_{r}$ can be improved to increase the amount of received power while both of $S_{i}$ and $\lambda$ are unchangeable.

\footnotetext{
*Corresponding Author: hayder.almizan@uokufa.edu.iq
} 
The second point is about the polarization of RF harvesting antenna. Circular polarization for RF harvesting antenna is strongly desirable since the antenna orientation becomes independent of the incident electromagnetic polarization [4].

The last design point considerable in this paper is the antenna coverage area $(A C A)$ to collect $\mathrm{RF}$ incident electromagnetic waves. Increasing $A C A$ can maximize the received power due to increase the incident waves angles. At the same time, increasing of $A C A$ causes decreasing $G_{r}$. Obviously, omnidirectional antenna can fit this point perfectly [5]. However, the inconvenience of use an omnidirectional antenna for RF harvesting is due to the difficulty of include the circular polarization and high gain.

In this paper, $A C A$ limitation angles are assumed to equal antenna Half-Power Beam Width (HPBW) angles $(\varphi, \theta)$. Now, the received antenna gain is inversely proportional with HPBW [6], or

$$
G_{r} \propto \frac{1}{A C A}
$$

Consequently, widen the $A C A$ always causes to lower antenna gain. This result is inevitable.

Many researches work on RF harvesting antenna design and enhancement. [7] utilized shorted ring slot antenna for circular polarization in GSM 900 band. A dipole antenna array with sequential rotation feeding was introduced in [8]. In [9], circular polarization is formed via differentiallyfed while the omnidirectional antenna is realized by compacting back-to-back patch antenna. A patch of tapered-slit octagonal-shaped was employed to achieve the circular polarization as well as wide-beam in [10]. Authors of [11] presented a design of monopole antenna with circular polarization for RF harvesting for wireless sensor node. The design of [12] has been achieved circular polarization by adapting the position and size of two peripheral cuts. In [13], the circular polarization was made via slotted-two circular-patch radiator with an electromagnetic coupling feed.

The aim of this paper is to design CircularlyPolarized (CP) wide-range coverage azimuth and elevation angles microstrip antenna for $\mathrm{RF}$ harvesting. Based on the parametric studies and curve fitting, the goal of present paper is achieved.

\section{Antenna Geometry and Design}

Fig. (1) shows the main parts of the proposed microstrip antenna structure. These parts are single coaxial feed, ground, substrate and the microstrip patch.

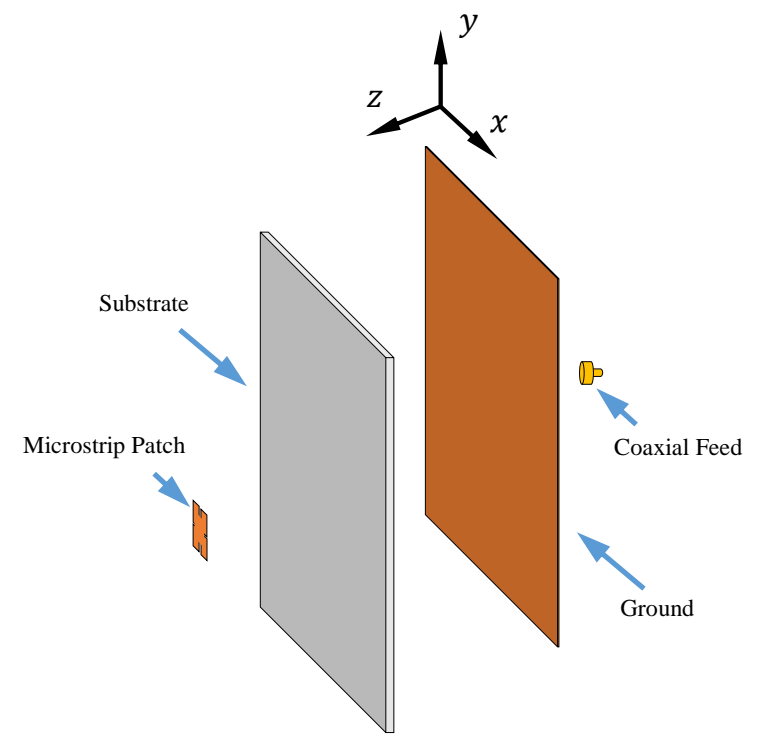

Figure 1. Parts of the proposed antenna structure.

Coaxial single feed $(50 \Omega)$ is of width $(3 \mathrm{~mm})$ and located at $(x=0, y=-4.5, z=0) \mathrm{mm}$. The ground plane is made of tiny thickness of copper material stick on the FR4 substrate of $2 \mathrm{~mm}$ thickness with $\epsilon_{r}=4.3$ and $\tan \delta=0.0025$. The patch mountains the other side of the substrate with dimensions are listed in Table 1.

The proposed microstrip antenna radiation is $\mathrm{CP}$. In other words, the proposed antenna has the ability to generate two orthogonal modes with a quadrature phase and equal magnitude. 
$\mathrm{CP}$ microstrip antenna can easily achieve via dual coaxial feed. But, using single coaxial feed is less complicated and losses. The proposed microstrip antenna is realized the circular polarization by Forming 2 diagonal truncated-edges and 4 orthogonal etched-slots and as seen in Fig. 2.

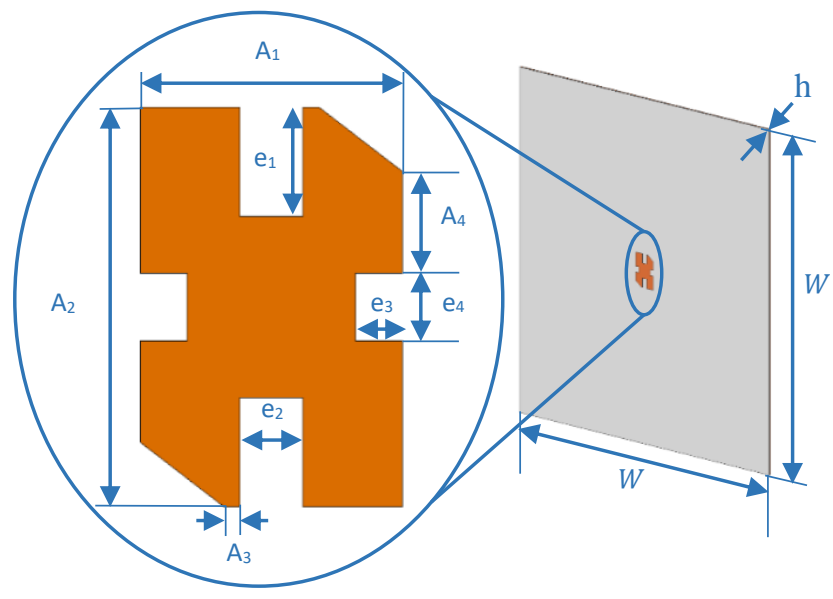

Figure 2. The proposed microstrip antenna geometry.

Table 1. The proposed microstrip antenna dimensions.

\begin{tabular}{|cc|}
\hline parameter & Dimension $(\mathrm{mm})$ \\
\hline$W$ & 280 \\
$\mathrm{~h}$ & 2 \\
$\mathrm{~A}_{1}$ & 19.31 \\
$\mathrm{~A}_{2}$ & 27.43 \\
$\mathrm{~A}_{3}$ & 1.17 \\
$\mathrm{~A}_{4}$ & 6.98 \\
$\mathrm{e}_{1}$ & 7.51 \\
$\mathrm{e}_{2}$ & 4.66 \\
$\mathrm{e}_{3}$ & 3.44 \\
$\mathrm{e}_{4}$ & 4.65 \\
\hline
\end{tabular}

Based on the time-dependent rotation of the electric field distribution with different time instants, the $\mathrm{CP}$ operating mechanism of the propose microstrip antenna can be validated. Fig. 3 illustrates the rotation of the electric field distribution at $\omega t=0^{\circ}, 45^{\circ}, 90^{\circ}$ and $135^{\circ}$ on the proposed microstrip patch antenna. Mainly, the field distributions are around the truncated edges and etching slots of the microstrip antenna which confirm the $\mathrm{CP}$ radiation from the proposed antenna.

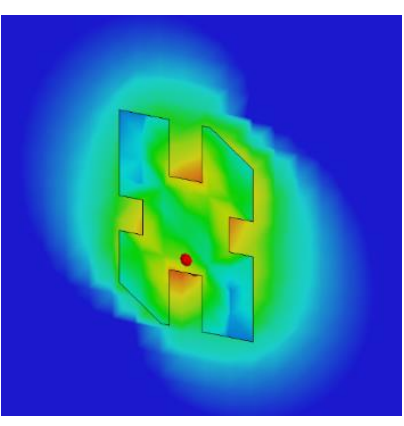

(a)

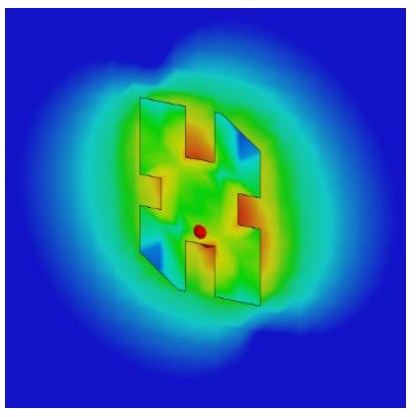

(c)

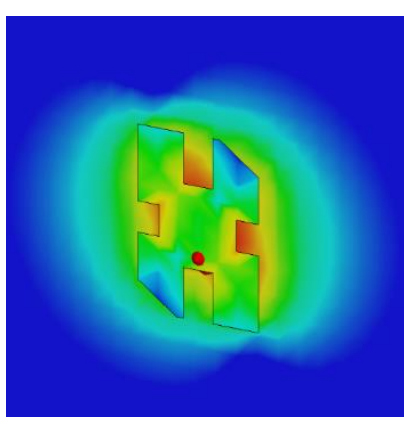

(b)

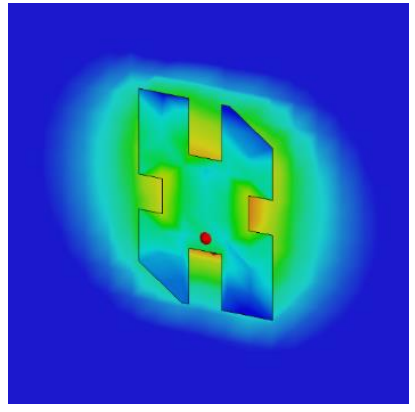

(d)
Figure 3. Electric field distribution at $2.45 \mathrm{GHz}$ with different time variants.

\section{Parametric Study of The CP Patch Antenna}

The parametric study of $\mathrm{CP}$ patch antenna is established to explore two groups of parameters changes effects. The first group (A-group) is about 2 diagonal truncated-edges. As seen in Fig. 4, the Axial Ratio (AR) is extremely sensitive to length changes of $\left(\mathrm{A}_{3}\right.$ or $\left.\mathrm{A}_{4}\right)$. Also, increasing length of $\left(A_{3}\right.$ or $\left.A_{4}\right)$ leads to increase the value of resonant frequency $\left(f_{r}\right)$ while decreasing $\left(\mathrm{A}_{3}\right.$ or $\mathrm{A}_{4}$ ) length results to shorten the $f_{r}$.

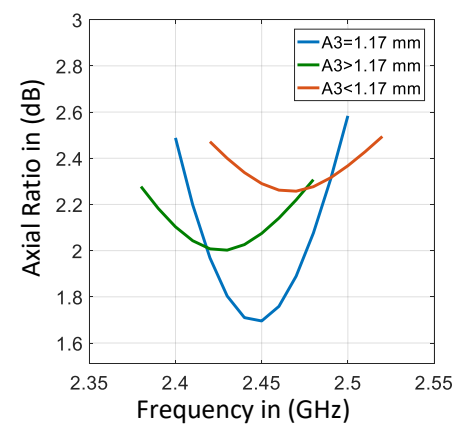

(a)

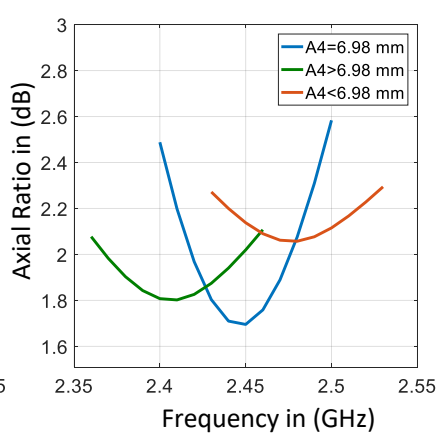

(b)
Figure 4. Effects of (A3, A4) lengths changes on AR and $f_{r}$. 
The second group (e-group) is concerned about the 4 orthogonal etched-slots. In general, length change of $\left(\mathrm{e}_{1}, \mathrm{e}_{2}, \mathrm{e}_{3}\right.$ or $\left.\mathrm{e}_{4}\right)$ slot perturbates the Axial Ratio. Increasing the slot length shifts the $f_{r}$ into a higher value while the desecrating slot length shrinks $f_{r}$. Fig. 5 shows the effects of slots length change on $\mathrm{AR}$ and $f_{r}$. Eventually, it is notable that (A-group) and (e-group) behavior inversely with respect to the $f_{r}$.

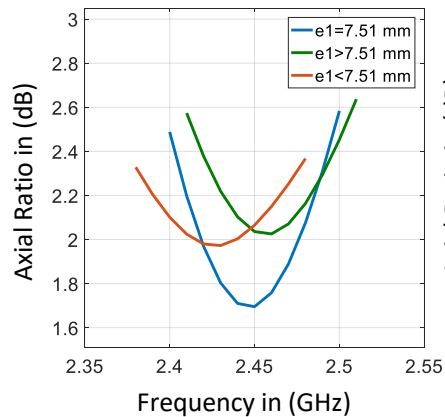

(a)

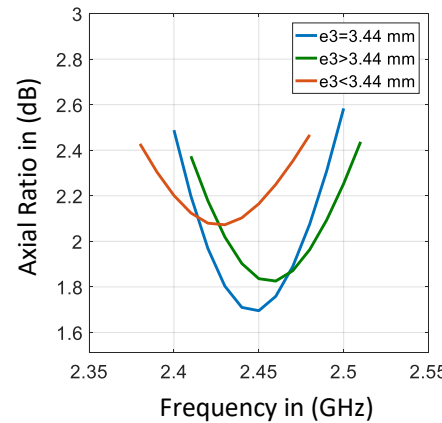

(c)

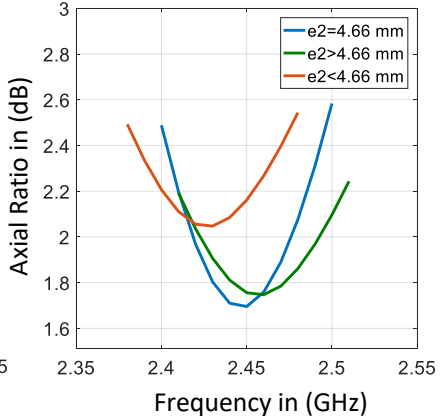

(b)

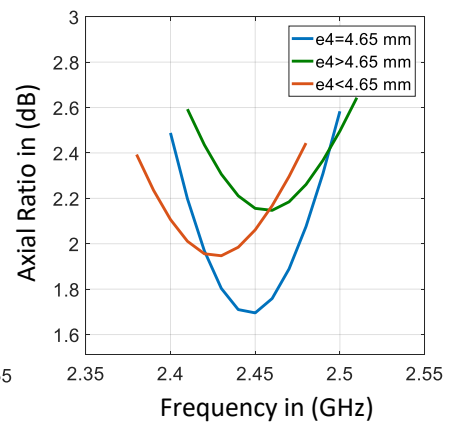

(d)
Figure 5. Effects of slots lengths changes on AR and $f_{r}$.

\section{Parametric Study of Ground-Substrate Area}

The following parametric study is conducted to find the relationship between the $G_{r}$ and the $A_{g s}$. The Ground-Substrate dimensions start with $(100 \mathrm{~mm} \times 100 \mathrm{~mm})$ and increase by $(50 \mathrm{~mm} \times 50 \mathrm{~mm})$ as step to reach (350 $\mathrm{mm} \times 350 \mathrm{~mm}$ ).

Now, with supposing that: the proposed antenna angles of azimuth and elevation are equal to the angles of the HPBW. The $A C A$, in antenna azimuth-elevation coordinate system which is clarified in Fig. 6, is given by [3]:

$$
A C A=\int_{\varphi_{\circ}}^{\varphi_{f}} \int_{\theta_{\circ}}^{\theta_{f}} r^{2} \sin \theta d \theta d \varphi
$$

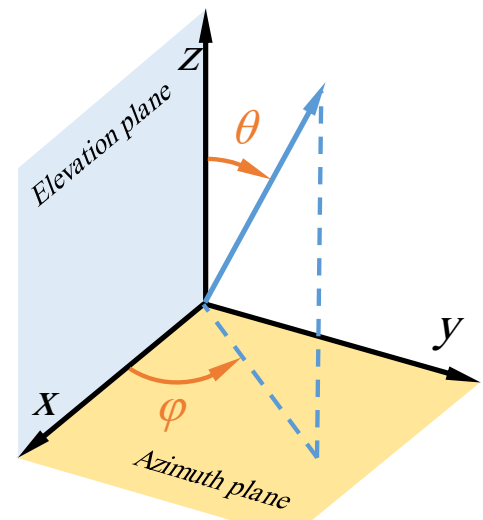

Figure 6. Antenna azimuth-elevation coordinate system.

where $r$ is the distance from the center of the patch antenna to the point of measurement, $\varphi$ and $\theta$ are the azimuth and elevation angles respectively. Besides, the Azimuth plane is $x y$-plane while the Elevation plane is $x z$-plane.

The parametric study shows slightly shift (increasing or decreasing) in $f_{r}$ with respect to $A_{g s}$ dimensions change. Also, $G_{r}$ increases while $A C A$ decreases and vice versa. The numerical results of $f_{r}$, return loss $\left|\mathrm{S}_{11}\right|, G_{r}, \mathrm{HPBW}$ as well as $A C A$ and Front-to-Back (F/B) ratio are listed in Table (2).

Table 2. Parametric study of Ground-Substrate Area.

\begin{tabular}{ccccccc}
\hline $\begin{array}{c}\text { Dimensions } \\
(m m)\end{array}$ & $\begin{array}{c}f_{r} \\
(\mathrm{GHz})\end{array}$ & $\begin{array}{c}\left|\mathrm{S}_{11}\right| \\
(\mathrm{dB})\end{array}$ & $\begin{array}{c}G_{r} \\
(\mathrm{dBi})\end{array}$ & $\begin{array}{c}\mathrm{HPBW} \\
(\varphi, \theta)\end{array}$ & $\begin{array}{c}A C A \\
(r=1 \mathrm{~m}) \\
\left(m^{2}\right)\end{array}$ & $\begin{array}{c}\mathrm{F} \\
\text { B }\end{array}$ \\
\hline $100 \times 100$ & 2.451 & -31 & 1.76 & $\left(79^{\circ}, 81^{\circ}\right)$ & 1.163 & 10 \\
\hline $150 \times 150$ & 2.450 & -33 & 1.46 & $\left(97^{\circ}, 112^{\circ}\right)$ & 2.327 & 7.7 \\
\hline $200 \times 200$ & 2.450 & -38 & 1.55 & $\left(98^{\circ}, 117^{\circ}\right)$ & 2.486 & 7.6 \\
\hline $250 \times 250$ & 2.450 & -32 & 1.51 & $\left(102^{\circ}, 115^{\circ}\right)$ & 2.532 & 7.1 \\
\hline $300 \times 300$ & 2.450 & -36 & 1.34 & $\left(72^{\circ}, 131^{\circ}\right)$ & 2.081 & 10 \\
\hline $350 \times 350$ & 2.451 & -33 & 1.61 & $\left(81^{\circ}, 124^{\circ}\right)$ & 2.204 & 9 \\
\hline
\end{tabular}

Fig. 7 is depicted the parametric data of the $G_{r}$ versus the $A_{g s}$. Curve fitting for these data is made using second degree of polynomial as a model function. The resulting polynomial is: 


$$
G_{r}\left(A_{g s}\right)=1.33+\left[10^{-10}\left(A_{g s}-78500\right)^{2}\right]
$$

or

$$
G_{r}(W)=1.33+\left[10^{-10}\left(W^{2}-78500\right)^{2}\right]
$$

where $G_{r}$ is in $(\mathrm{dBi}), A_{g s}$ in $\left(\mathrm{mm}^{2}\right)$, and $W$ is the length (or width) of the proposed antenna as defined previously.

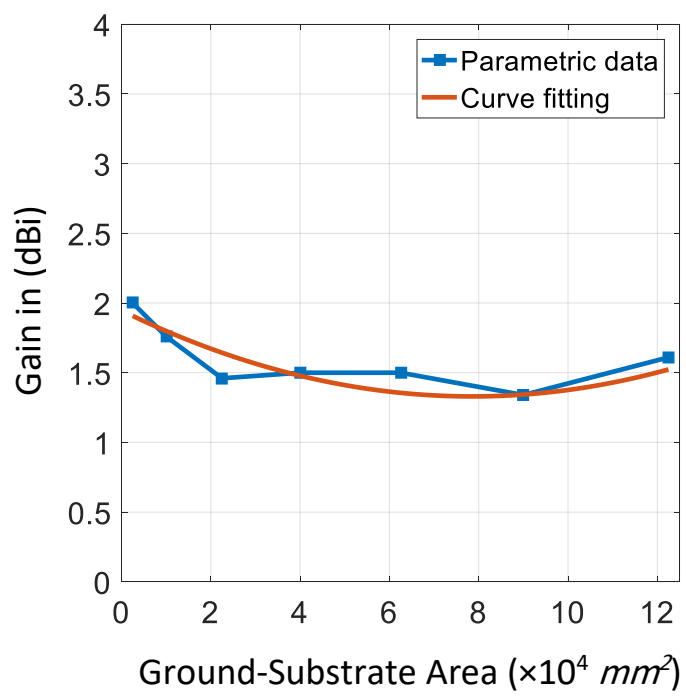

Figure 7. Parametric data and curve fitting.

Now, the largest $A C A$ can be indicated by finding the minimum value of the received antenna gain. According to (2), the largest $A C A$ is found when $W$ equals to $280 \mathrm{~mm}$. The simulated results show that: $f_{r}=2.450 \mathrm{GHz},\left|\mathrm{S}_{11}\right|=-33 \mathrm{~dB}, G_{r}=1.33$ $\mathrm{dBi}, \quad \varphi=84^{\circ}, \quad \theta=137^{\circ},\left.\quad A C A\right|_{r=1 \mathrm{~m}}=$ $2.538 \mathrm{~m}^{2}$, and $(\mathrm{F} / \mathrm{B})=7.2$. In terms of $A C A$, the last obtained value considers larger than any other $A C A$ between the range of $(100 \mathrm{~mm} \leq W \leq 350 \mathrm{~mm})$.

\section{Fabrication and Measurements}

The proposed $\mathrm{CP}$ microstrip antenna was fabricated and tested to validate the simulated design. Fig. 8 shows the front and back sides of the proposed antenna prototype.

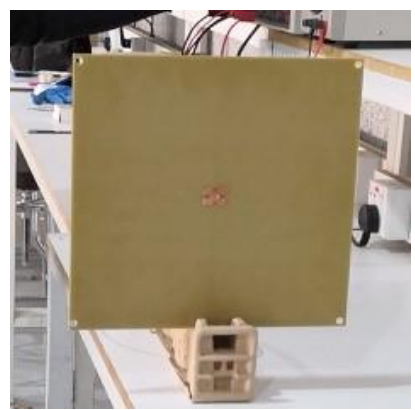

(a)

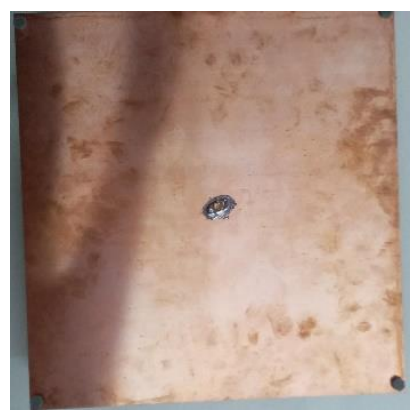

(b)
Figure 8. Antenna prototype (a) front side (b) back side.

The antenna performance in terms of $\left|S_{11}\right|$ spectra, gain spectra, AR, and radiation patterns are measured using a typical measurement system. The used system is based on coaxial cables, vector network analyzer of Agilent PNA 8720 series, and 82357A USB to GPIB interface that is connected to an external computer. The antenna is placed on a rotational holder inside an RF anechoic chamber as seen in Fig. 9.
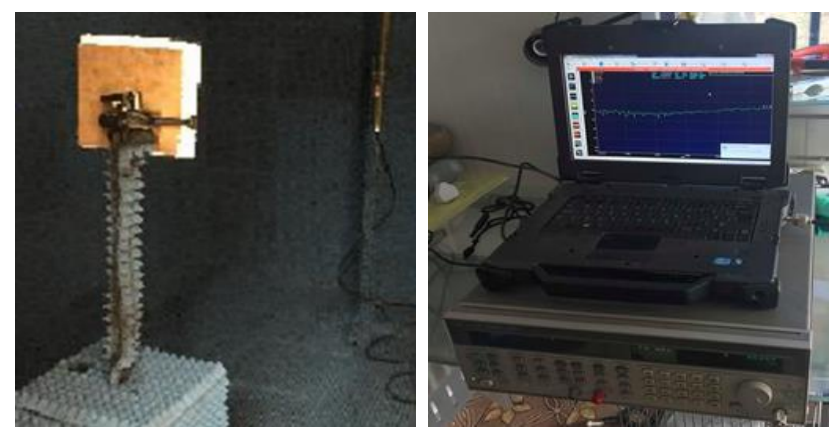

Figure 9. Antenna measurement setup inside the RF anechoic chamber.

The simulated and measured $\left|\mathrm{S}_{11}\right|$ spectra, obtained gain as well as AR values over the frequency range, (2.3-2.55) $\mathrm{GHz}$, are shown in Fig. 10. Firstly, Fig. 10 (a) represents $\left|\mathrm{S}_{11}\right|$ spectra for the antenna and the $f_{r}$ is indicated at $2.45 \mathrm{GHz}$. Next, the antenna gain spectra is plotted in Fig. 10 (b) where the maximum gain value is found at $2.45 \mathrm{GHz}$ about $1.33 \mathrm{dBi}$. Lastly, the simulated and measured results of the AR is shown in Fig. 10 (c) where AR is lower than $3 \mathrm{~dB}$ at $2.45 \mathrm{GHz}$. 


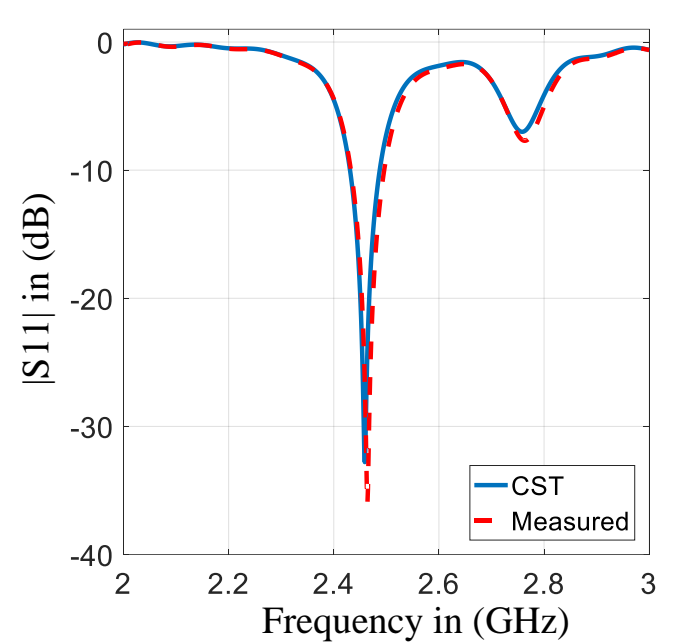

(a)

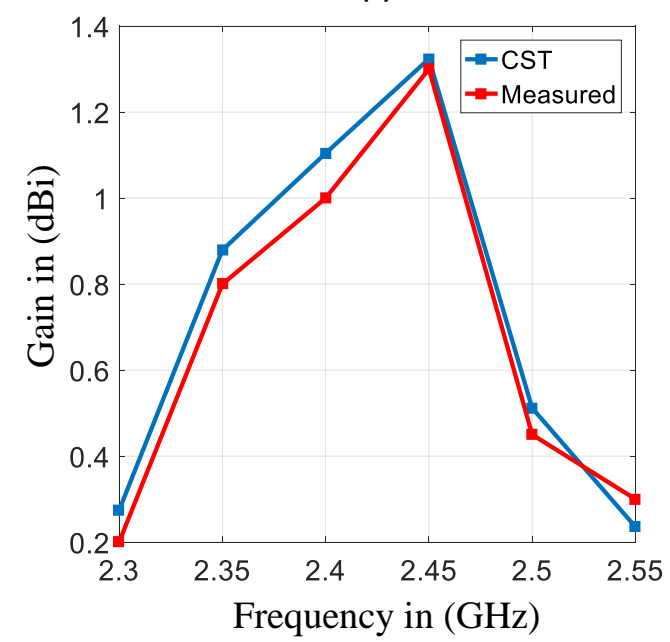

(b)

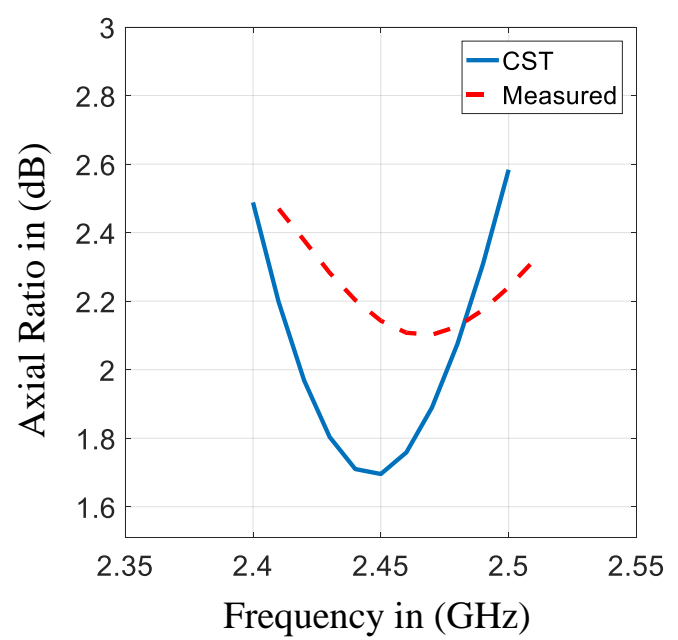

(c)

Figure 10. Simulated and measured results for (a) $\left|S_{11}\right|$ (b) Gain spectra. (c) Axial Ratio.

The presented results in Fig. 11 show a comparison between both of the simulated and measured radiation patterns at two perpendicular planes $\mathrm{E}$ and $\mathrm{H}$. Clearly, the proposed $\mathrm{Cp}$ microstrip antenna radiation pattern covers a wide beam width of $\varphi=84^{\circ}$ or $\left(-42^{\circ}\right.$ to $\left.+42^{\circ}\right)$ and $\theta=137^{\circ}$ or $\left(-68.5^{\circ}\right.$ to $\left.+68.5^{\circ}\right)$ with gain of 1.33 $\mathrm{dBi}$.
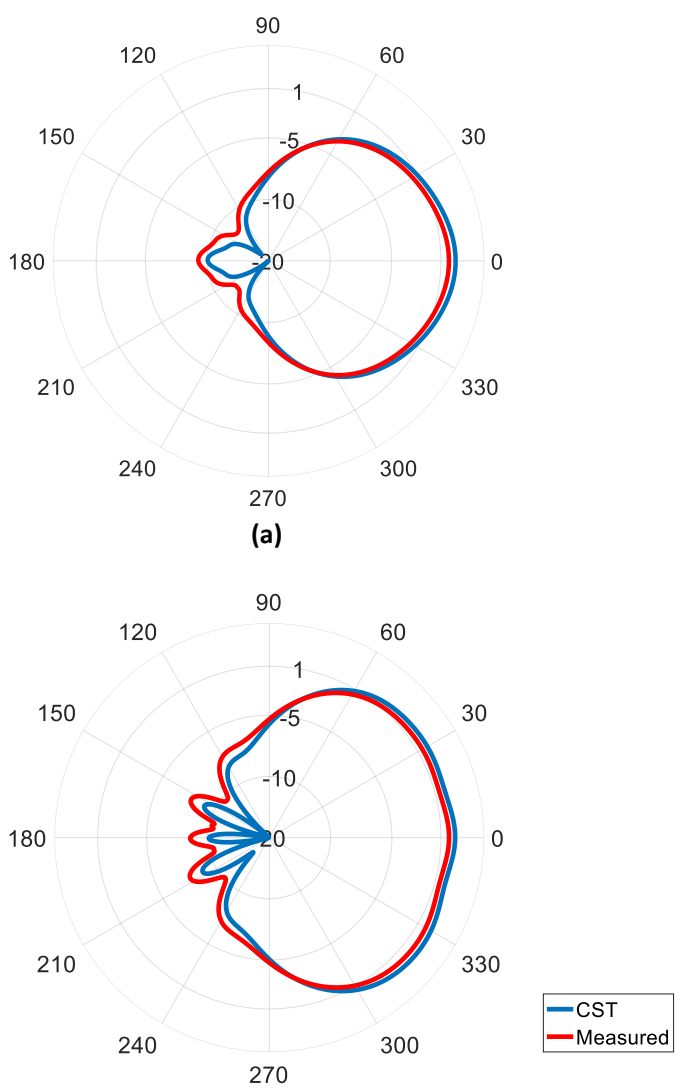

(b)

Figure 11. Radiation patterns based on simulated and measured results for the proposed antenna: (a) E-plane (b) H-plane.

\section{Conclusions}

In this paper, a $\mathrm{CP}$ microstrip antenna for $\mathrm{RF}$ harvesting has been proposed. The circular polarization is achieved using 2 diagonal truncated-edges and 4 orthogonal etched-slots in the patch. Two parametric studies were conducted to find some of the antenna dimensions effects on specific antenna characteristics. The first parametric study was concerned about exploring the polarization of the 
proposed antenna when truncations and slots dimensions are changed. Circular polarization as well as $f_{r}$ of the proposed antenna showed sensitivity to the change of patch geometry. The second parametric study was about changing ground-substrate area effects on the received antenna gain. This study indicated that: the azimuth and elevation angles of the proposed $\mathrm{CP}$ microstrip antenna could be controlled by ground -substrate area dimensions. Based on the last study data, a mathematical model connects both of $G_{r}$ and $A_{g s}$ was proposed via curve fitting with polynomial of second degree. The model function was used to find the maximum $A C A$ to grantee the maximum RF harvesting since the gain value is inversely propositional with HPBW $(\varphi, \theta)$. The final Ground-Substrate dimensions are $280 \mathrm{~mm} \times 280 \mathrm{~mm}$ with coverage anglers are ranged $\left(-42^{\circ}\right.$ to $\left.+42^{\circ}\right)$ for azimuth angle $\varphi$ and $\left(-68.5^{\circ}\right.$ to $\left.+68.5^{\circ}\right)$ for elevation angle $\theta$ while antenna gain is almost $1.33 \mathrm{dBi}$.

\section{Conflict of interest}

The authors declare that there is no conflict of interest.

\section{References}

1. Aboualalaa, M. Abdel-Rahman, A. B. Allam, A. Elsadek, H. and Pokharel, R. K. (2017). Design of a Dual-Band Microstrip Antenna with Enhanced Gain for Energy Harvesting Applications. IEEE Antennas and Wireless Propagation Letters, vol. 16, pp. 1622-1626.

2. Elwi, T. A. Almukhtar Tawfeeq, O. Alnaiemy, Y. Ahmed, H. S. and Lajos, N. (2018)." A UWB Monopole Antenna Design based RF Energy Harvesting Technology". Third Scientific Conf. of Electrical Engineering (SCEE), Baghdad, pp. 111-115.

3. Liu, R. Wang, X. Nie, D. Wang, L. Cui, W. Wang, M. Zheng H. and Li, E. (2019). Metasurface: Enhancing gain of antenna and energy harvesting system design. International Journal of RF and Microwave ComputerAided Engineering, vol. 30, pp. 1-11.

4. Bernard, L., Nasimuddin and Alphones, A. (2016). AN e-shaped slotted-circular-patch antenna for circularly polarized radiation and radiofrequency energy harvesting. Microwave and Optical Technology Letters, vol. 58 , pp. $868-875$.

5. Bernard, L., Nasimuddin and Alphones, A. (2016). Teo-shaped slotted-circular-patch antenna for circularly polarized radiation and RF energy harvesting. Microwave and Optical Technology Letters, vol. 57, pp. 27522758.

6. Balanis, C. A. (2016). "Antenna Theory: Analysis and Design". $4^{\text {th }}$ ed., Wiley.

7. Ghosh, S. (2015). "Design and testing of $R F$ energy harvesting module in GSM 900 band using circularly polarized antenna". IEEE Int. Conf. on Research in Computational Intelligence and Communication Networks (ICRCICN), Kolkata, pp. 386-389.

8. Bui, T. D. Nguyen, Q. C. and Le, M. T. (2017). "Novel wideband circularly polarized antenna for wireless applications". IEEE Asia Pacific Microwave Conf. (APMC), Kuala Lumpar, pp. 430-433.

9. Bao, X. Yang, K. O'Conchubhair, O. and Ammann, M. J. (2016). "Differentially-fed omnidirectional circularly polarized patch antenna for RF energy harvesting". 10th European Conf. on Antennas and Propagation (EuCAP), Davos, pp. 1-5.

10. Jie, A. M. Nasimuddin, Karim, M. F. and Chandrasekaran, K. T. (2019). A Wide-Angle Circularly Polarized Tapered-Slit-Patch Antenna with a Compact Rectifier for EnergyHarvesting Systems. IEEE Antennas and Propagation Magazine, vol. 61, No. 2, pp. 94111.

11. Ghosh, S. Ghosh S. K. and Chakrabarty, A. (2014). "Design of RF energy harvesting 
system for wireless sensor node using

circularly polarized monopole antenna: RF energy harvesting system for WSN node using circularly polarized antenna". The 9th Int. Conf. on Industrial and Information Systems (ICIIS), Gwalior, pp. 1-6.

12. Huang, F. Yo, T. Lee C. and Luo, C. (2012). Design of Circular Polarization Antenna with Harmonic Suppression for Rectenna Application. IEEE Antennas and Wireless Propagation Letters, vol. 11, pp. 592-595.

13. Jie, A. M. Nasimuddin, Karim, M. F. Bin, L. Chin F. and Ong, M. (2016). "A proximitycoupled circularly polarized slotted-circular patch antenna for RF energy harvesting applications". IEEE Region 10 Conf. (TENCON), Singapore, pp. 2027-2030. 